\title{
Efeitos Sensoriais em Jogos Cognitivos para Idosos: Jogo do Stroop
}

\author{
Gustavo Lopes de Paula ${ }^{1}$, Luiz Felipe de Melo ${ }^{1}$, Mayara Helena dos Santos ${ }^{1}$, \\ Flávio L. Seixas ${ }^{1}$, Rosimere F. Santana ${ }^{2}$, Débora C. Muchaluat-Saade ${ }^{1}$ \\ ${ }^{1}$ Laboratório MídiaCom - Universidade Federal Fluminense (UFF) \\ ${ }^{2}$ Departamento de Enfermagem - Universidade Federal Fluminense (UFF)
}

\{gustavolp, lfmatosmelo, mayarahelena, debora, fseixas\}@midiacom.uff.br

rosifesa@gmail.com

\begin{abstract}
Recent research has shown that virtual games stimulate the brain in a way that is beneficial to the user's health, and these are widely used as an aid to the treatment of diseases related to aging. In addition, studies elucidate the use of sensory effects in the treatment of psychopathologies. In this way, this paper proposes the Stroop Game, a cognitive game based on the Stroop test, with a light sensory effect. The game was developed for the Brazilian digital TV, using the Ginga-NCL middleware. After running Stroop Game tests with elder users, we conclude that the game proposed in this paper was well accepted by the users and that the sensory effect influenced their perception about it, making the game more attractive.
\end{abstract}

Resumo. Pesquisas realizadas recentemente revelam que os jogos virtuais estimulam o cérebro de uma forma benéfica à saúde do usuário, portanto, esses vêm sendo amplamente utilizados como um auxílio ao tratamento de doenças relacionadas ao envelhecimento. Além disso, estudos elucidam que o uso de efeitos sensoriais é eficaz no tratamento de psicopatologias. Dessa maneira, este artigo propõe o Jogo do Stroop, um jogo cognitivo baseado no teste de Stroop, com a presença de um efeito sensorial de luz. O jogo foi desenvolvido para a TV digital brasileira, utilizando o middleware Ginga-NCL. Após a realização de testes do Jogo do Stroop com idosos em uma oficina de memória cognitiva, conclui-se que o jogo proposto neste trabalho teve uma boa aceitação entre os voluntários e que o efeito sensorial altera a percepção do jogador, tornando-o mais atrativo.

\section{Introdução}

Nos últimos anos, pesquisas científicas no meio acadêmico, principalmente nas áreas relacionadas à computação com enfoque na melhoria da qualidade de vida do ser humano, têm estudado a correlação entre efeitos sensoriais e o tratamento de doenças neurológicas como a demência [Taher et al. 2015]. Simultaneamente, pesquisas que avaliam a relação entre jogos eletrônicos e a capacidade cognitiva mostram que esses jogos trazem benefícios a diversos processos como a percepção, atenção, associação, memória [Oei and Patterson 2013], raciocínio e pensamento.

A maior parte dos jogos cognitivos existentes atualmente, que trabalham as bases da saúde cognitiva são desenvolvidos para desktops, tablets e smartphones. Embora estes dispositivos estejam presentes no cotidiano brasileiro, idosos apresentam dificuldades 
em utilizá-los ou usam apenas os serviços básicos oferecidos pelos gadgets como fazer ligações e mandar mensagens de texto [Mohadisdudis and Ali 2014]. Dessa maneira, os benefícios gerados por tais jogos acabam não alcançando todo o público idoso, sendo esse um dos grupos que mais se beneficiariam do acesso às aplicações, devido à perda da capacidade cognitiva proveniente do avançar da idade. Na tentativa de contornar esse problema, nota-se a necessidade da elaboração de jogos para outros dispositivos eletrônicos que sejam mais familiares aos idosos.

Em vista disso, plataformas online, em grande parte comerciais, surgiram disponibilizando uma grande variedade de jogos que estimulam as funções cognitivas citadas anteriormente e, por conseguinte, melhoram a saúde mental do usuário. Entretanto, para utilizá-las, são necessários diversos artifícios que muitas vezes são desconhecidos do idoso, como o acesso à Internet e conhecimentos básicos de utilização do computador ou gadgets móveis. Por esse motivo, o público idoso acaba excluído dos benefícios trazidos por essa inovação e sofrendo com a impossibilidade de usufruir das plataformas devido à falta de familiaridade com as tecnologias necessárias para a utilização da mesma.

Com o televisor sendo o meio de comunicação mais popular do Brasil [Governo Brasileiro 2014], estando presente em 97, 2\% [IBGE 2018] das residências, é notável que aplicações multimídia para o sistema televisivo tenham maior poder de alcance. A popularidade, simplicidade e estabilidade da televisão na vida e no cotidiano dos cidadãos brasileiros geram uma maior aceitação por parte dos idosos em utilizá-la, em relação a computadores, celulares e outros dispositivos eletrônicos móveis.

Na tentativa de explorar essa proximidade do idoso com essa tecnologia específica, surge a possibilidade de criação de aplicações multimídia como jogos cognitivos para a TV digital brasileira. O Sistema Brasileiro de Televisão Digital (SBTVD) viabiliza esta proposta, ao disponibilizar o middleware Ginga [NBR 15606-2:2011 2011], utilizando as linguagens NCL (Nested Context Language) [Soares and Barbosa 2011] e Lua [Ierusalimschy 2006] para desenvolvimento de aplicações multimídia para TV digital. Os programas NCLua - como são chamados tais programas multimídia - são executados no middleware, que possiblita a transmissão das aplicações para telespectadores de todo o país por meio do veículo de comunicação. A linguagem declarativa NCL é utilizada a fim de criar relações temporais e espaciais entre mídias diversas como imagens, vídeos e áudios dentro de um documento multimídia. Lua é a linguagem de programação empregada para a escrita dos scripts procedurais que são associados e operam em conjunto com os documentos NCL, através de comunicação por eventos. Um exemplo de jogo cognitivo desenvolvido para o SBTVD é o MemoGinga [Matos et al. 2018].

Este artigo propõe um novo jogo cognitivo destinado a idosos e acessível através da TV, chamado de Jogo do Stroop. Visando estudar os tópicos supracitados quanto à relação entre idosos, televisão e jogos cognitivos, o Jogo do Stroop tem um diferencial em relação a propostas anteriores, pois oferece efeito sensorial de luz, integrado de forma sincronizada ao jogo, que permite um estímulo multissensorial ao usuário idoso. Mesmo sendo uma aplicação interativa para TV digital, o Jogo do Stroop não exige a presença de uma canal de interatividade no receptor de TV digital do usuário, pois utiliza apenas interatividade local.

O presente artigo estrutura-se da seguinte maneira. A Seção 2 aborda trabalhos 
relacionados ao Jogo do Stroop. A Seção 3 aborda a relação entre jogos e exercícios cognitivos. Já a Seção 4 descreve o teste e efeito que dá nome ao jogo, enquanto a Seção 5 detalha o funcionamento do jogo proposto e sua implementação, incluindo detalhamento sobre os dispositivos de hardware utilizados para efeitos luminosos. A Seção 6 aborda os testes do Jogo do Stroop realizados com idosos em uma oficina de memória cognitiva. Finalmente, a Seção 7 finaliza o artigo destacando conclusões e trabalhos futuros.

\section{Trabalhos Relacionados}

A ideia de utilizar jogos para terapias cognitivas já vem sido explorada e possibilitou a criação de plataformas online como "Lumosity"[Lumos Labs, Inc 2014], "Brain HQ"[Posit Science 2016] e "CogniFit"[Shlomo Breznitz 1999].

A plataforma online Lumosity explora diversas áreas para produzir seus jogos cognitivos, tentando agregar uma ludicidade aos treinamentos. Ao começar a utilizá-la, o usuário deve realizar alguns testes para definir o perfil do mesmo e sugerir os testes e jogos recomendados. Os jogos são divididos entre algumas das bases da capacidade cognitiva como velocidade, memória, atenção, flexibilidade e solução de problemas. Porém, para usufruir desse serviço, é necessário comprar um plano, restringindo o uso daqueles que possuem baixo poder aquisitivo. Ademais, por ser acessada pela Internet, o usuário precisa ter conhecimentos de como utilizar um computador ou celular. Dessa forma, o público idoso, que possui uma dificuldade de utilizar esses dispositivos, encontra um obstáculo na busca de uma ferramenta para ajudar com esses treinamentos.

A plataforma Brain $H Q$ segue a mesma ideia da Lumosity. Seus jogos são divididos em categorias como cérebro, socialização, inteligência, orientação, memória e atenção. Um diferencial em relação à plataforma anterior é que a Brain $H Q$ dispõe metas para que o jogador as cumpram e mantém um histórico dos resultados obtidos nos jogos, permitindo avaliar se houve uma evolução.

A CogniFit é uma ferramenta online assim como as anteriores. Seus treinamentos são repartidos em categorias cognitivas sendo elas memória, percepção espacial, concentração, aritmética mental e em categorias voltadas para auxiliar em doenças e tratamentos específicos como depressão, quimioterapia, Parkinson, insônia, acidente vascular cerebral, entre outros. Essa plataforma utiliza critérios que ela chama de domínios cognitivos para distribuir a pontuação do usuário. Esses domínios são atenção, memória, coordenação e raciocínio. Também possibilita que o jogador observe a sua evolução através de gráficos. Entretanto, da mesma forma que as outras citadas anteriormente, a CogniFit é paga e acessada pelo computador ou por smartphones, dificultando o uso por idosos.

Na tentativa de superar essa barreira existente do acesso à rede, do conhecimento necessário e do poder aquisitivo para usufruir desses treinamentos cognitivos, surgiu o interesse de fazê-los para a televisão, o dispositivo mais familiar para o idoso e com o maior poder de alcance. Um exemplo desses jogos é o MemoGinga[Matos et al. 2018], onde busca-se treinar a memória do usuário. Apresentando três níveis, no primeiro é exibida uma figura geométrica colorida para o jogador que o mesmo deve memorizar e depois comparar com uma segunda imagem, dizendo se são iguais ou não. Nos níveis dois e três, é necessário memorizar um grupo dessas formas e dizer se a nova figura apresentada estava presente no grupo mostrado anteriormente. 
Visando aproveitar todas as vantagens descritas de utilizar a TV em relação a computadores e smartphones e estender os estudos dos já realizados quanto a produção de testes cognitivos para este mesmo dispositivo, o Jogo de Stroop acrescenta um efeito sensorial ao gameplay e busca avaliar como isso interfere na relação com o idoso.

\section{Jogos e Exercícios Cognitivos}

Saúde cognitiva e qualidade de vida andam lado a lado na vida do idoso. É sabido que, com o avançar da idade, ocorre uma perda das capacidades cognitivas, sendo uma das causas a dificuldade de codificação e recuperação de informações [da Costa Pinto 1999]. $\mathrm{Na}$ busca de tentar amenizar essas deficiências cognitivas advindas do envelhecimento, treinamentos cognitivos foram desenvolvidos para estimular a mente do idoso. Estudos já mostram que idosos com pontuação alta em testes cognitivos possuem uma maior independência e melhor qualidade de vida [Barnes et al. 2007]. Assim como foi descoberto que é possível condicionar a flexibilidade cognitiva, permitindo melhorá-la. Tais descobertas vêm aumentando o interesse em pesquisar métodos de melhorar as capacidades mentais e reduzir os danos do envelhecimento.

$\mathrm{Na}$ relação entre jogos e como eles afetam a vida dos jogadores mais velhos, foi observado que um grupo de idosos submetidos a treinamentos cognitivos desenvolveu uma melhora no processamento controlado, atenção e memória imediata e de longo prazo em relação ao grupo de controle [Ballesteros et al. 2014]. Além desses benefícios, foi observado que esses usuários apresentam uma maior autoconfiança e aceitação social. Dessa forma, é possível concluir que jogos virtuais são uma forma viável de melhorar a cognição de seus usuários.

Além de explorar a pesquisa em jogos cognitivos voltados a idosos, este trabalho também tem como foco o estudo de como efeitos sensoriais podem influenciar o interesse de idosos por jogos cognitivos e também se efeitos sensoriais influenciam a eficácia de jogos para trabalhar as atividades cognitivas em idosos.

\section{Teste e Efeito de Stroop}

Em 1935, John Ridley Stroop publicou um artigo no "Journal of Experimental Psychology" chamado "Studies of interference in serial verbal reactions" [Stroop 1935]. O artigo de Stroop foi de suma importância para a psicologia experimental. No seu projeto, foram realizados três experimentos a fim de estudar a reação do cérebro quando exposto a uma discordância entre a leitura e visualização de cores.

No primeiro experimento, os voluntários deviam ler nomes de cores presentes em formulários sorteados aleatoriamente, sendo uma parte escrita em coloração diferente dos nomes das cores - por ex. "azul" não aparecia escrito em coloração azul - e a outra parte escrita em preto. No segundo experimento, os nomes de cores eram escritos em qualquer cor, esta podendo ser ou não concordante com a palavra. Dessa vez, o voluntário deveria passar pelo obstáculo de confusão devido a diferença de cores e dizer qual era a cor na qual a palavra estava colorida. Além disso, existiam no experimento quadrados que eram coloridos e o voluntário deveria dizer nome da cor do mesmo. No terceiro experimento, os testes anteriores foram refeitos com algumas modificações, como a troca do quadrado colorido - no experimento 2 - pelo formato de suásticas, que por sua vez facilitam a observação da cor branca. 
Sintetizando as respostas dos voluntários aos experimentos acima, Stroop elucidou que a discordância entre nome da cor e a coloração da palavra geram um maior tempo de reação quando o indivíduo é exposto ao teste, além de que nesses casos o índice de erro por parte do indivíduo também é maior.

\section{Jogo do Stroop}

\subsection{Características e Regras do Jogo}

O Jogo do Stroop foi desenvolvido com o objetivo de treinar a capacidade de atenção seletiva dos idosos através da exploração do efeito Stroop. Baseado no teste de mesmo nome, o jogo funciona da seguinte forma: é exibido o nome de uma cor ao jogador, porém, ela está colorida e o jogador deve dizer qual é a cor do texto. A tela inicial possui as opções de iniciar o jogo e de ir para a tela de regras. Para selecionar a opção desejada, o usuário deve apertar o botão do controle com a respectiva cor. A Figura 1 mostra a tela inicial do Jogo do Stroop.
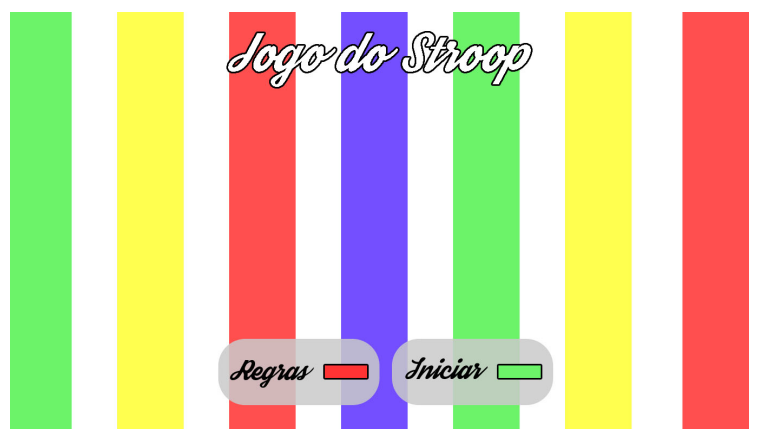

Figura 1. Tela inicial do jogo.

Após selecionar para iniciar o jogo, será exibida a tela de jogo. Uma vez dentro dessa tela, será selecionada uma imagem aleatória dentre as imagens presentes. Essas imagens representam nomes das quatro cores dos botões coloridos presentes no controle remoto de um receptor de TV digital, sendo elas vermelho, verde, amarelo e azul. Cada uma das quatro cores é escrita nessas mesmas quatro cores distintas, gerando as dezesseis imagens. Portanto, um exemplo de imagem seria a palavra azul escrita na cor vermelho. Com a imagem sorteada sendo exibida ao jogador, o mesmo deve identificar qual é a coloração da imagem. Para marcar a resposta, é necessário pressionar o botão cuja cor ele considera a resposta correta ou selecionar por meio das teclas direcionais presentes no controle e selecionar o botão presente na tela. Tal processo se repete por dez turnos até chegar ao fim da partida. A Figura 2 ilustra a tela durante a partida e a seleção da resposta correta deste exemplo de imagem.

Ao fim da partida, o jogo irá para seu estado final, onde apresentará os resultados da partida, sendo eles o tempo de duração da partida e a quantidade de acertos. A Figura 3 ilustra a tela de fim de jogo e os resultados indicados.

\subsection{Efeito Sensorial Luminoso}

Para a criação dos efeitos sensoriais, foi utilizado um microcontrolador ESP8266 NodeMCU e uma fita de LED. Para a comunicação do jogo com o microcontrolador foi utilizado o protocolo MQTT [Hunkeler et al. 2008]. Este protocolo segue o modelo 


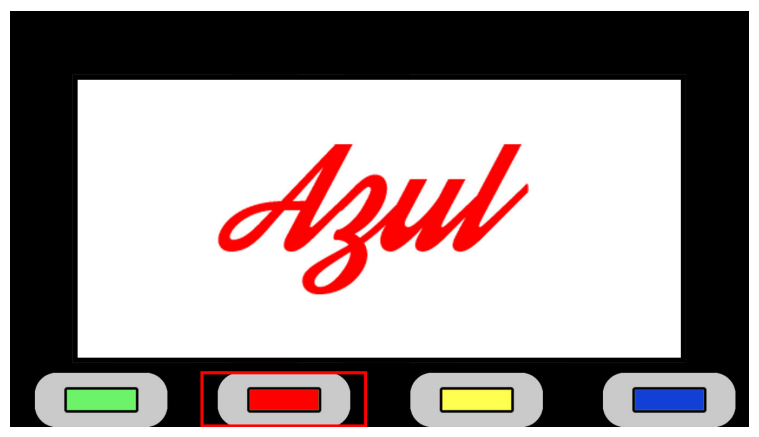

Figura 2. Tela do jogo durante a partida.

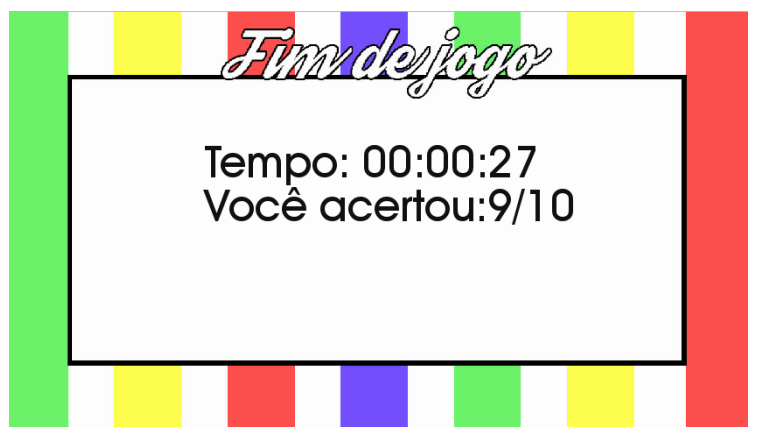

Figura 3. Tela de fim de jogo.

Publisher-Subscriber, onde o Publisher publica os dados que desejar na forma de um tópico, uma barra e a mensagem propriamente dita - por ex. tópico/mensagem. Essa mensagem é enviada para um broker, que é responsável por encaminhar as mensagens aos destinatários. Esses últimos, por sua vez, são chamados de Subscribers, pois informam ao broker quais tópicos eles desejam receber. A Figura 4 esquematiza o funcionamento do modelo Publisher-Subscriber usado pelo protocolo MQTT.

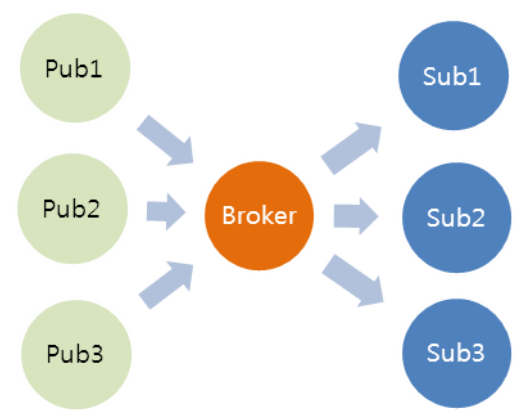

Figura 4. Esquema Publisher-Subscriber do protocolo MQTT.

Para a implementação do efeito, foi necessária a instalação de uma biblioteca para a linguagem Lua versão 5.2 chamada Paho [Eclipse Foundation, Inc. 2012] no middleware Ginga. A partir disso, o jogo já consegue mandar mensagens para o broker dizendo qual cor deve acender, toda vez que uma nova imagem é apresentada. Foi necessário instalar o ambiente de desenvolvimento para programar placas Arduino [Arduino LLC 2005] e um gerenciador de placas [Ivan Grokhotkov and Michael Molinari 2015], que torna possível escrever programas 
para o microcontrolador ESP8266 NodeMCU. Também foi preciso instalar uma biblioteca MQTT para Arduino [Nick O’Leary 2009] para implementar o protocolo descrito. Para executar o componente broker, foi empregado um desktop Mac Mini, que se comunica com o receptor de TV digital através de uma rede local sem fio.

Uma vez resolvida a parte da comunicação entre o jogo e a placa controladora, foi implementada a interação entre a placa e a fita de LED. Para isso foi fundamental encontrar uma biblioteca que facilitasse a implementação. Por isso foi escolhida a Adafruit NeoPixel Library [Adafruit Industries 2012]. Portanto, a comunicação final se dá da seguinte maneira: o jogo envia o código em escala RGB da cor para o broker e o mesmo encaminha para o microcontrolador, que, por sua vez, acende a fita de LED com o código da cor recebida. A Figura 5 exibe a fita de LED utilizada na implementação enquanto a Figura 6 exibe o efeito visual produzido pela mesma em uma TV. Na Figura 7 está representado o esquema final da integração entre o jogo, broker e microcontrolador.

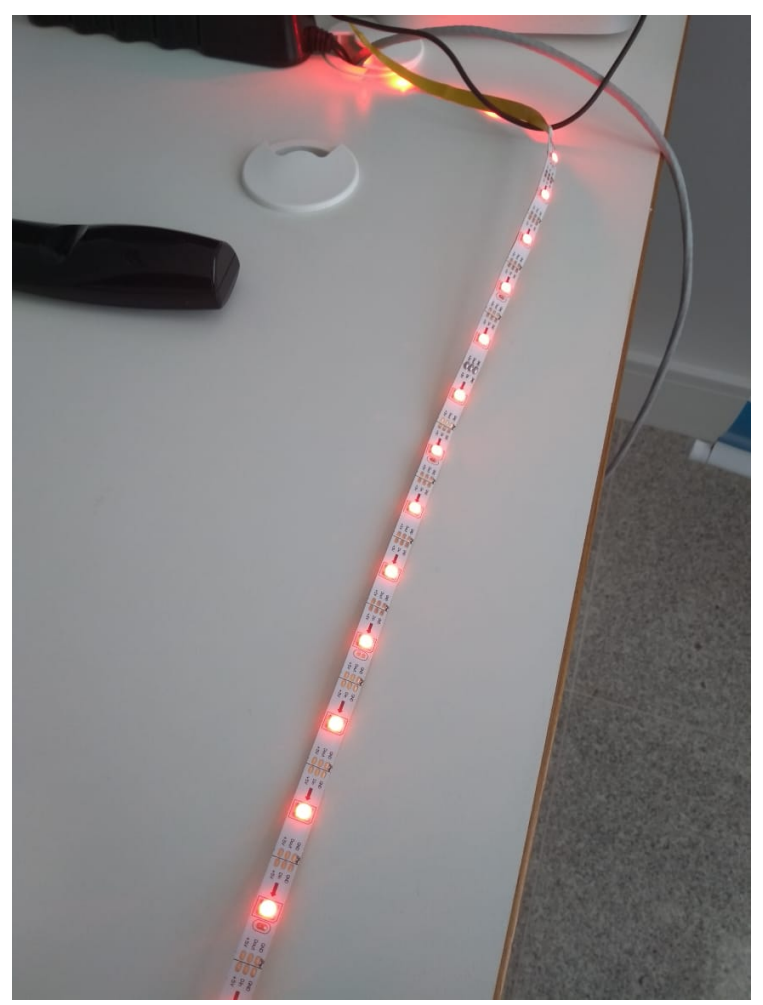

Figura 5. Fita de LED.

\section{Testes com Idosos}

Os testes foram realizados em três sessões em dias diferentes, junto à oficina de memória cognitiva que é oferecida gratuitamente à população idosa, com autorização da professora responsável pela oficina e aprovado pelo comitê de ética da UFF, com número de parecer 250.132. Na primeira sessão, os testes foram executados sem o efeito de luz, para avaliar fatores como jogabilidade, dificuldade e aceitação dos usuários. Dessa forma, os idosos jogavam uma partida e em seguida respondiam a um questionário SUS (System Usability Scale) [Brooke 1996]. Esse questionário é constituído por 10 afirmações sobre o sistema avaliado e o participante deve dizer seu grau de concordância de acordo com uma escala 


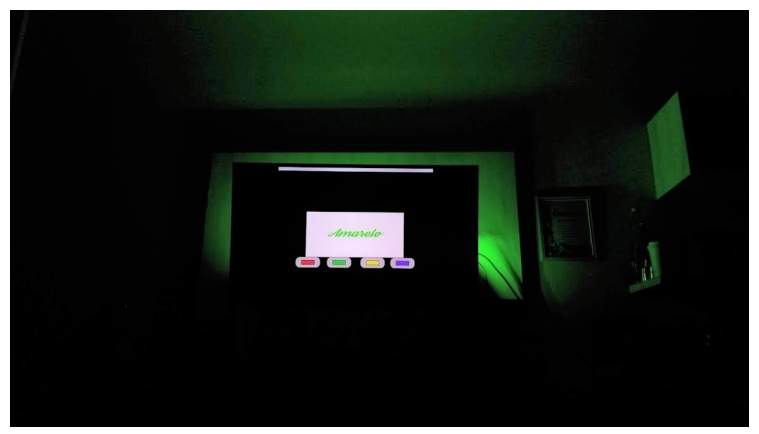

Figura 6. Efeito projetado.

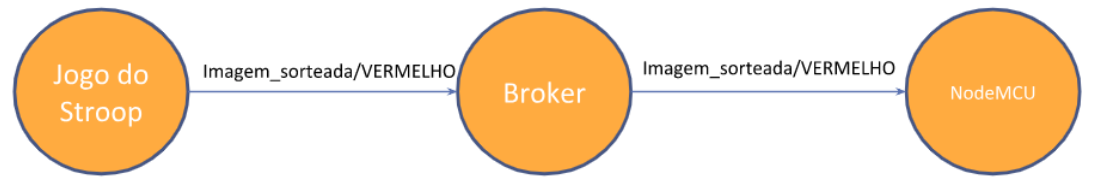

Figura 7. Integração dos componentes do jogo.

de 1 (discordo totalmente) a 5 (concordo totalmente). O modelo SUS foi escolhido por ser bastante utilizado para análise de usabilidade de sistemas de software, devido à sua baixa complexidade e por sua objetividade, facilitando a obtenção de respostas. Seu objetivo é avaliar fatores como efetividade, que observa se o usuário conseguiu completar o objetivo, eficiência, que observa o esforço feito pelo usuário e sua satisfação com o sistema utilizado. Para calcular a nota final após o questionário, é necessário, para as perguntas ímpares, subtrair uma unidade da pontuação respondida e, para as pares, subtrair a nota obtida de cinco - por ex. se o usuário respondeu 2, contabilize 3. Por último é necessário multiplicar por 2,5 a soma dos valores obtidos com as contas descritas anteriormente, o que dá um valor máximo de 100. Os resultados obtidos podem ser vistos na Tabela 1.

Tabela 1. Resultados da primeira sessão de testes.

\begin{tabular}{|l|c|c|c|c|c|}
\hline Idade (anos) & Escolaridade & Tempo (min) & Acertos (Porcentagem) & Possui queixas de memória? & Placar SUS \\
\hline 67 & Fundamental & $1: 02$ & $30 \%$ & Sim & 42,5 \\
\hline 69 & Superior & $1: 45$ & $100 \%$ & Sim & 55 \\
\hline 74 & Fundamental & $1: 34$ & $60 \%$ & Não & 80 \\
\hline 75 & Superior & $2: 02$ & $60 \%$ & Sim & 92,5 \\
\hline 76 & Médio & $1: 54$ & $100 \%$ & Sim & 65 \\
\hline 76 & Fundamental & $1: 26$ & $90 \%$ & Sim & 70 \\
\hline 77 & Médio & $0: 26$ & $60 \%$ & Não & 97,5 \\
\hline 81 & Fundamental & $1: 21$ & $70 \%$ & Sim & Sim \\
\hline 82 & Médio & $2: 00$ & $40 \%$ & & Média $=74,72$ \\
\hline Média $=75,22$ & & Média $=1: 30$ & Média $=67,8 \%$ & & Desvio Padrão $=18,26$ \\
\hline Desvio Padrão $=4,89$ & & Desvio Padrão $=0: 31$ & Desvio Padrão $=24,88 \%$ & &
\end{tabular}

Uma pontuação SUS acima de 68 indica que o sistema possui usabilidade satisfatória [Bangor et al. 2008]. Portanto, ao possuir uma média de 74,72, o Jogo de Stroop mostra-se adequado para o uso por idosos. Tais dados estão em conformidade com o que foi observado durante os testes. Uma vez explicado como jogar o jogo, os participantes não apresentaram muitas dúvidas sobre como proceder, assim como foi observado que eles achavam que outros participantes conseguiriam aprender a utilizar o jogo com certa facilidade. Além disso, os participantes disseram que acharam o jogo interessante e que gostariam de jogar novamente. 
De acordo com a Tabela 1, nota-se que o tempo para finalização da tarefa aumenta de acordo com a idade do usuário, mostrando que há uma maior interferência do efeito Stroop com o avançar da idade, mostrando consistência com outros estudos na literatura [Kwong See and Ryan 1995]. É possível reparar também que o grau de escolaridade não apresenta muita relevância para completar a tarefa. Outro fato observado é que nos casos de menores quantidades de acertos, os participantes começavam acertando, mas após algumas rodadas, começavam a se distrair e confundir qual era a resposta correta e acabavam errando, indo de acordo com a teoria da inibição do envelhecimento cognitivo [Hasher and Zacks 1988].

Na segunda sessão de testes, o jogo foi testado com o efeito de luz, porém com pessoas que não participaram do primeiro teste. Dessa forma, o primeiro contato delas com o jogo já contou com essa funcionalidade a mais. Visando observar como o efeito influenciava a satisfação do usuário com o sistema, os participantes responderam o mesmo questionário SUS utilizado no primeiro dia. A Tabela 2 mostra os resultados desta sessão de testes.

Tabela 2. Resultados da segunda sessão de testes.

\begin{tabular}{|l|c|c|c|c|c|c|}
\hline Idade $(\operatorname{anos})$ & Escolaridade & Tempo $(\mathrm{min})$ & Acertos $(\%)$ & Placar SUS & Acredita que o efeito influenciou. & O efeito tornou o jogo mais interessante. \\
\hline 64 & Superior & $1: 37$ & $40 \%$ & 65 & Discorda Totalmente & Concorda Totalmente \\
\hline 67 & Médio & $1: 35$ & $40 \%$ & 80 & Discorda Totalmente & Discorda Totalmente \\
\hline 69 & Médio & $1: 19$ & $60 \%$ & 90 & Discorda Totalmente & Discorda Totalmente \\
\hline 77 & Superior & $0: 23$ & $100 \%$ & 100 & Discorda Totalmente & Concorda Parcialmente \\
\hline 81 & Médio & $2: 50$ & $80 \%$ & 92,5 & Concorda Totalmente & Concorda Parcialmente \\
\hline 82 & Médio & $2: 14$ & $70 \%$ & 80 & Discorda Totalmente & Concorda Totalmente \\
\hline 83 & Médio & $1: 05$ & $70 \%$ & 97,5 & Discorda Totalmente & Concorda Parcialmente \\
\hline Média $=74,7$ & & Média $=1: 34$ & Média $=65,7 \%$ & Média $=86,43$ & & \\
\hline Desvio Padrão $=7,89$ & \multicolumn{7}{|l|}{ Desvio Padrão $=0: 47$} & Desvio Padrão $=21,5 \%$ & Desvio Padrão $=12,23$ & & \\
\hline
\end{tabular}

Conforme a Tabela 2, é possível observar que o efeito de luz, que no caso analisado indicava a cor correta da resposta, causou um impacto positivo no jogo referente à usabilidade, possuindo uma média da pontuação do SUS superior à do teste sem o efeito. Segundo relatos dos usuários, embora eles acreditem que o efeito não tenha influenciado no resultado, os mesmos, em sua maioria disseram que a presença dele torna o jogo mais interessante. Além disso, percebe-se novamente que os usuários com idades elevadas levam em geral mais tempo para terminar a partida.

Na terceira sessão de teses, foi avaliado se o efeito de luz influenciava os resultados de pessoas que já haviam jogado sem o efeito. Para isso, o efeito foi programado para acender com a cor da resposta correta, tentando fazer com que os jogadores acertassem mais. Nos mesmos moldes dos testes anteriores, essas pessoas jogavam uma partida, porém por questões de tempo, não foi possível que respondessem o questionário SUS. Dessa forma, as perguntas feitas foram apenas sobre o efeito de luz. Os dados obtidos podem ser vistos na Tabela 3 .

Tabela 3. Resultados da terceira sessão de testes.

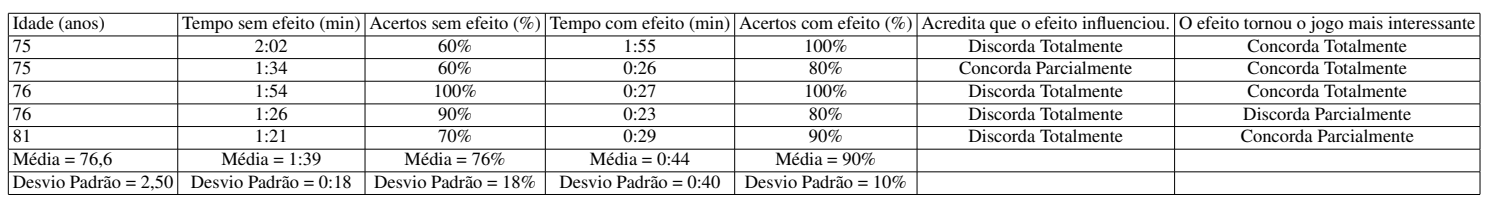

Percebe-se, de acordo com a Tabela 3, que embora os participantes digam que o efeito não afetou na jogabilidade, alegando que eles se concentraram apenas na tela 
do jogo, ignorando o resto, houve uma melhora no tempo de finalização da tarefa e na quantidade de acertos. Porém, devido ao número pequeno de participantes, não é possível concluir que esta melhora provém apenas do efeito, já que existem outros fatores como uma segunda explicação sobre o jogo, caso eles tenham esquecido as regras e ser o último dia da oficina antes das férias. Já no aspecto da usabilidade, quatro dos cinco participantes concordaram que o efeito tornou o jogo mais interessante em relação à versão sem essa função. Com isso, percebe-se que o efeito luminoso agrega uma maior aceitabilidade ao jogo, e, consequentemente, aumenta o engajamento dos idosos com o treinamento cognitivo proposto pelo Jogo do Stroop.

\section{Conclusões}

De acordo com o resultados dos testes de usabilidade, o Jogo de Stroop teve grande aceitação perante os idosos, apresentando potencial para ser utilizado como ferramenta de auxílio à prevenção e tratamento de doenças do envelhecimento. Além disso, concluise que os efeitos sensoriais alteraram as impressões deles sobre a aplicação, tornando-a mais atrativa e consequentemente aumentando a aceitação do jogo entre membros do público-alvo.

Como trabalhos futuros, pretende-se realizar mais testes devido ao pequeno número de voluntários e, em seguida, integrar o Jogo do Stroop com sensores eletrônicos, como um monitor de batimentos cardíacos. O objetivo da introdução dos sensores será descobrir como a experiência do jogo afeta a saúde do idoso.

Outro trabalho interesse é o uso de novas formas de interação através de gestos ou captura de movimentos dos olhos para tornar o jogo mais fácil de ser jogado, evitando teclas do controle remoto da TV. Além disso, pretende-se implementar diferentes níveis do jogo, como uma versão em que a cor errada é usada para o efeito luminoso, ao invés da cor certa. Outra opção é limitar o tempo para resposta, no qual o idoso tem um intervalo de segundos para responder a cada uma das rodadas do jogo, o que elevará o nível de dificuldade.

\section{Agradecimentos}

Este trabalho foi parcialmente financiado pelo CNPq, CAPES, FAPERJ, FAPESP e INCTMACC.

\section{Referências}

Adafruit Industries (2012). NeoPixel Library. https://github.com/adafruit/Adafruit_NeoPixel. Acessado: 03 fev. 2019.

Arduino LLC (2005). Arduino. https://www.arduino.cc/. Acessado: 03 fev. 2019.

Ballesteros, S., Prieto, A., Mayas, J., Toril, P., Pita, C., de León, L. P., Reales, J. M., and Waterworth, J. (2014). Brain training with non-action video games enhances aspects of cognition in older adults: a randomized controlled trial. Frontiers in Aging Neuroscience, 6:277.

Bangor, A., Kortum, P. T., and Miller, J. T. (2008). An empirical evaluation of the system usability scale. International Journal of Human-Computer Interaction, 24(6):574594. 
Barnes, D. E., Cauley, J. A., Lui, L.-Y., Fink, H. A., McCulloch, C., Stone, K. L., and Yaffe, K. (2007). Women who maintain optimal cognitive function into old age. Journal of the American Geriatrics Society, 55(2):259-264.

Brooke, J. (1996). Sus: a quick and dirty usability scale. In Usability Evaluation in Industry. Taylor Francis.

da Costa Pinto, A. (1999). Problemas de memória nos idosos: Uma revisão. Psicologia, Educação e Cultura, 3:253-295.

Eclipse Foundation, Inc. (2012). Paho. https://www.eclipse.org/paho/. Acessado: 03 fev. 2019.

Governo Brasileiro (2014). Levantamento governamental. http://www.brasil.gov.br/governo/2014/12/televisao-ainda-e-o-meio-de-comunicacaopredominante-entre-os-brasileiros. Acessado: 18 jan. 2018.

Hasher, L. and Zacks, R. T. (1988). Working memory, comprehension, and aging: A review and a new view. In Psychology of learning and motivation, volume 22, pages 193-225. Elsevier.

Hunkeler, U., Truong, H. L., and Stanford-Clark, A. (2008). Mqtt-s-a publish/subscribe protocol for wireless sensor networks. In Communication systems software and middleware and workshops, 2008. comsware 2008. 3rd international conference on, pages 791-798. IEEE.

IBGE (2018). Acesso à internet e à televisão e posse de telefone móvel celular para uso pessoal : 2016. IBGE.

Ierusalimschy, R. (2006). Programming in Lua, Second Edition. Lua.Org.

Ivan Grokhotkov and Michael Molinari (2015). Arduino core for esp8266 wifi chip. https://github.com/esp8266/Arduino. Acessado: 03 fev. 2019.

Kwong See, S. T. and Ryan, E. B. (1995). Cognitive mediation of adult age differences in language performance. Psychology and Aging, 10(3):458.

Lumos Labs, Inc (2014). Lumosity. https://www.lumosity.com/. Acessado: 18 jan. 2018.

Matos, L. F., Santos, M. H., Boechat, Y., Amorim, G., and Muchaluat-Saade, D. C. (2018). Memoginga: Jogo interativo para tv digital como exercício cognitivo para idosos. In $18^{\circ}$ Simpósio Brasileiro de Computação Aplicada à Saúde (SBCAS 2018), volume 18. SBC.

Mohadisdudis, H. M. and Ali, N. M. (2014). A study of smartphone usage and barriers among the elderly. In User Science and Engineering (i-USEr), 2014 3rd International Conference on, pages 109-114. IEEE.

NBR 15606-2:2011 (2011). Televisão digital terrestre - codificação de dados e especificações de transmissão para radiofusão digital parte 2: Ginga-ncl para receptores fixos e móveis - linguagem de aplicação xml para codificação de aplicações. Standard, Associação Brasileira de Normas Técnicas.

Nick O'Leary (2009). Arduino client for mqtt. https://github.com/knolleary/pubsubclient. Acessado: 03 fev. 2019. 
Oei, A. C. and Patterson, M. D. (2013). Enhancing cognition with video games: A multiple game training study. PLOS ONE, 8:1-16.

Posit Science (2016). BrainHQ. https://www.brainhq.com/. Acessado: 18 jan. 2018.

Shlomo Breznitz (1999). CogniFit. https://www.cognifit.com/. Acessado: 18 fev. 2019.

Soares, L. F. G. and Barbosa, S. D. J. (2011). Programando em NCL 3.0, 2a. Edição, Versão 2.1. Elsevier Campos.

Stroop, J. R. (1935). Studies of interference in serial verbal reactions. Journal of experimental psychology, 18(6):643.

Taher, A. V., Ahmadi, M. K., and Zamir, F. P. (2015). Effects of multi-sensory stimulation on cognition function, depression, anxiety and quality of life in elderly persons with dementia. 